\title{
Abiotic and biotic resistance to grass invasion in serpentine annual plant communities
}

\author{
Barbara Marie Going · Janneke Hillerislambers • \\ Jonathan M. Levine
}

Received: 22 August 2008 / Accepted: 8 December 2008 / Published online: 13 January 2009

(C) The Author(s) 2009. This article is published with open access at Springerlink.com

\begin{abstract}
Biological invasions severely impact native plant communities, causing dramatic shifts in species composition and the restriction of native species to spatially isolated refuges. Competition from resident species and the interaction between resource limitation and competition have been overlooked as mechanisms of community resistance in refugia habitats. We examined the importance of these factors in determining the resistance of California serpentine plant communities to invasion by three common European grasses, Avena barbata, Bromus diandrus, and Hordeum murinum. We added seeds of each of these grasses to plots subjected to six levels of resource addition $\left(\mathrm{N}, \mathrm{P}, \mathrm{Ca}, \mathrm{H}_{2} \mathrm{O}\right.$, all resources together, and a no-addition control) and two levels of competition (with resident community present or removed). Resource limitation and competition had strong effects on the biomass and reproduction of the three invaders. The addition of all resources together combined with the removal of the resident community yielded individual plants that were fourfold to 20-fold larger and sixfold to 20 -fold more fecund than plants from
\end{abstract}

Communicated by Meelis Partel.

B. M. Going $(\bowtie)$

Department of Environmental Science and Policy,

University of California, 3132 Wickson Hall,

Davis, CA 95616, USA

e-mail: bmgoing@ucdavis.edu

J. Hillerislambers

Department of Biology, University of Washington,

Seattle 98195, USA

e-mail: jhrl@u.washington.edu

J. M. Levine

Department of Ecology, Evolution, and Marine Biology,

University of California, Santa Barbara, CA 93106, USA

e-mail: levine@lifesci.ucsb.edu control plots. Competitor removal alone yielded invaders that were twofold to sevenfold larger and twofold to ninefold more fecund. $\mathrm{N}$ addition alone or in combination with other resources led to a twofold to ninefold increase in the biomass and fecundity of the invaders. No other resource alone significantly affected native or invader performance, suggesting that $\mathrm{N}$ was the key limiting resource during our experiment. We found a significant interaction between abiotic and biotic resistance for Bromus, which experienced increased competitive suppression in fertilized plots. The threefold increase in resident biomass with $\mathrm{N}$ addition was likely responsible for this result. Our results confirm that serpentine plant communities are severely $\mathrm{N}$ limited, which, in combination with competition from resident species, promotes the resistance of these systems to invasions. Our work suggests that better understanding the relative sensitivities of invaders and residents to the physical environment is critical to predicting how abiotic and biotic factors interact to determine community resistance.

Keywords Community resistance $\cdot$ Grassland · Interaction $\cdot$ Resource limitation $\cdot$ Competition

\section{Introduction}

The ecological and economic consequences of biological invasions have motivated tremendous interest in the factors enabling communities to resist these invasions. While the overwhelming focus of past work has been biotic resistance, the reduction in invasion success caused by resident consumers, competitors, or disease (Elton 1958; Alpert et al. 2000; Levine et al. 2004; Mitchell et al. 2006), there is a growing awareness of the importance of abiotic factors that contribute to community resistance. These factors 
include low resource availability and other environmental stresses (Davis et al. 2000; D'Antonio et al. 2001; Davis and Pelsor 2003; Barger et al. 2003; Richardson and Pyšek 2006). However, the effect of the interactions among abiotic and biotic sources of community resistance on the success of invaders is only beginning to be understood. Moreover, the few studies on these interactions that exist come primarily from animal systems (e.g., Byers 2002; Holway et al. 2002).

Abiotic factors can control the success of an invader directly. Stressful environments (e.g., deserts) generally have fewer numbers and a lower abundance of invasive species at broad spatial scales (Randall et al. 1998; Lonsdale 1999; Alpert et al. 2000). A number of experimental studies have also demonstrated that stressful environments become more invasible when limiting resources are added (Burke and Grime 1996; Barger et al. 2003; Leishman and Thomson 2005). For example, the addition of $\mathrm{N}$ increased the density and abundance of exotic annual grasses in the Mojave Desert (Brooks 2003) and promoted exotic tree invasion in a Texas coastal prairie (Siemann and Rogers 2007). The addition of limiting resources may also interact with a decrease in resource competition (e.g., disturbance), to even further increase invader success (Burke and Grime 1996; Barger et al. 2003).

The abiotic environment can also affect invasions by influencing the outcome of biotic interactions (Byers 2002; Holway et al. 2002), generating an interaction between these two sources of resistance. Such interactions can amplify or dampen overall community resistance. Invaders that are already physiologically stressed by the abiotic environment may be particularly vulnerable to negative interactions with the resident community (D'Antonio 1993; Alpert et al. 2000; Levine et al. 2004). Alternatively, abiotic stress may reduce the ability of the resident community to achieve the necessary abundance and biomass to repel invaders through competitive effects. The nature of interactions between biotic and abiotic factors depends on the relative tolerances of the residents and the invader to the stresses imposed by their environment.

Recently, several hypotheses have been proposed to integrate the factors that influence community resistance to invasion (e.g., Davis et al. 2000; D'Antonio et al. 2001; Huston 2004). For example, the fluctuating resource hypothesis suggests that communities become more vulnerable to invasions when resources are made more available, either because resource supply is increased or competition for resources is decreased (Davis et al. 2000). If, however, resource addition disproportionately favors resident competitors, an interaction between abiotic and biotic resistance, then increased resource supply can increase invasion resistance.

In this paper, we examine the roles of abiotic and biotic factors and their interaction in controlling the success of invasive species in a serpentine grassland. These systems are relatively stressful for plants, because of the chemical composition of their soils, and are dominated by native species. Thus, they are an ideal environment in which to examine the relative roles and interaction of biotic and abiotic resistance. In addition, the role of resource limitation in constraining grass invasion of these habitats is established (Huenneke et al. 1990), setting the stage to examine interactions between abiotic and biotic resistance. In general, serpentine soil is high in $\mathrm{Mg}, \mathrm{Fe}$ minerals, and heavy metals, and low in Ca, N, and P (Kruckeberg 2006). These chemical conditions are compounded by the shallow, rocky nature of many serpentine soils, which results in low waterholding capacity. The environmental stresses imposed by serpentine soils vary across the landscape, ranging from harsh shallow soils on rocky outcrops to deeper, more fertile soil with a higher organic matter content in the intervening matrix. Serpentine grasslands, like nearly all grasslands in California, have been invaded by European annual grasses, particularly species within the genera Avena, Bromus, and Hordeum. Invasions in serpentine grasslands are remarkably patchy. Invaders are most successful in deeper, more resource-rich soils, but invader density is low on serpentine outcrops, which remain dominated by native forbs and grasses despite a potentially large pool of non-native propagules (Harrison 1999; Gram et al. 2004).

We examined how resource limitation and the resident community influenced the growth and seed production of three invasive European annual grasses in serpentine communities. Although metal toxicity may be an important factor limiting productivity on serpentine soils, we focus here on nutrient limitation and competition because these factors are likely to play crucial roles in community resistance to invasion and are amenable to manipulation. Competition from the resident community has been largely overlooked as a mechanism of community resistance in serpentine grasslands because short-statured native species are generally considered to be poor competitors on more fertile non-serpentine soils (Brady et al. 2005). However, native species are adapted to the multiple stresses imposed by serpentine soils, and in these habitats, might effectively compete with the more poorly adapted invaders.

We predicted that both invasive and native species would respond positively to the addition of limiting resources, but that the invasive grasses would respond more strongly because these species are not adapted to the low resource conditions of the serpentine environment. We also expected a negative effect of competition from the resident community, but that this effect would be weak relative to resource availability because of the small stature and sparse cover of the resident community. 


\section{Materials and methods}

Study system

Our study was conducted at Sedgwick Reserve $\left(34^{\circ} 44^{\prime} 21^{\prime \prime} \mathrm{N}, 120^{\circ} 00^{\prime} 20^{\prime \prime} \mathrm{W}\right)$, a 2,364 -ha research reserve managed by the University of California, Santa Barbara. The climate is Mediterranean with an average annual precipitation of $38 \mathrm{~cm}$, most of which occurs as rainfall from January to March. Regional estimates for $\mathrm{N}$ depositions for Santa Barbara County range from 0 to $2 \mathrm{~kg} \mathrm{ha}^{-1}$ year $^{-1}$ (Takemoto et al. 1995), suggesting that anthropogenic effects on $\mathrm{N}$ inputs are minimal in this area. Our field site was a serpentine grassland located on south-facing slopes of the San Rafael range at an elevation of approximately $730 \mathrm{~m}$. The grassland is composed of several distinct outcrops of shallow, rocky serpentine soil, which grade into a matrix of deeper, more fertile serpentine soil with a higher organic matter content (Gram et al. 2004). The outcrops are dominated by native annual forbs and grasses. Plantago erecta, Vulpia microstachys, and Lasthenia californica were the most common species, present in 93, 80, and $61 \%$ of experimental plots, respectively. The matrix community is dominated by several non-native annual grasses, including Avena barbata, Bromus diandrus, Bromus madritensis, and Hordeum murinum. Gram et al. (2004) provide a detailed description of the plant communities of both the outcrop and matrix habitats. Although gopher disturbance has been reported to be an important determinant of invasion success in other serpentine grasslands (Hobbs et al. 1988), there was little gopher activity observed on the outcrops during the course of our study.

\section{Experimental design}

In October 2005 eight experimental blocks were placed on the serpentine outcrops in areas dominated by native annual forbs, with few perennial taxa. Each block was composed of twelve $20 \times 20$-cm plots that were randomly assigned to one of two competition treatments, uncleared and cleared, and to one of six resource addition treatments. Plots were placed at least $50 \mathrm{~cm}$ apart from each other. The resident vegetation from the six cleared plots was removed monthly by clipping plants as they emerged from the ground. The six resource addition treatments were additions of: $\mathrm{N}, \mathrm{P}$, $\mathrm{Ca}, \mathrm{H}_{2} \mathrm{O}$, all resources together, and no-addition controls.

$\mathrm{N}$ was added as slow-release pellets $\left(\mathrm{NH}_{2}\right) \mathrm{CO}(\mathrm{N}$ at $6.6 \mathrm{~g} \mathrm{~m}^{-2}$ year $\left.{ }^{-1}\right)$, $\mathrm{P}$ was added as powdered $\mathrm{KH}_{2} \mathrm{PO}_{4}(\mathrm{P}$ at $6.6 \mathrm{~g} \mathrm{~m}^{-2}$ year $\left.{ }^{-1}\right)$ and $\mathrm{Ca}$ was added as powered $\mathrm{CaCl}_{2}(\mathrm{Ca}$ at $6.36 \mathrm{~g} \mathrm{~m}^{-2}$ year $\left.^{-1}\right)$. Nutrient additions were modified from Huenneke et al. (1990) and were supplied in two equal applications in early December and early March. For the $\mathrm{H}_{2} \mathrm{O}$ addition treatment we added 2.51 of $\mathrm{H}_{2} \mathrm{O}$ (corresponding to $2.5 \mathrm{~cm}$ of rainfall) to plots 6 times in between rain events, supplementing the $65.3 \mathrm{~cm}$ of natural rainfall by an additional $16.5 \mathrm{~cm}$. The additional $\mathrm{H}_{2} \mathrm{O}$ was $50 \%$ of average precipitation, but only a $25 \%$ increase for our study year due to El Niño conditions.

Twenty-five seeds from each of three non-native annual grasses, A. barbata, B. diandrus, and H. murinum, were added to different $10 \times 10-\mathrm{cm}$ subplots within each plot. Seeds of all three non-native grasses were collected locally from a non-serpentine grassland, located less than $6 \mathrm{~km}$ from the field site. Following germination the nonnative grasses were randomly thinned to two individuals per subplot to minimize intraspecific competition and measurements on these individuals were averaged prior to analysis.

One of the four subplots was not seeded with any nonnative grass. We used this subplot to assess the response of the resident community to resource addition, leaving it unclipped even in the cleared treatments to increase our power to determine how the resident community responds to fertilization. Native biomass in uncleared and cleared treatments was averaged within resource treatments in each block prior to analysis.

\section{Harvesting}

Harvesting occurred during the second week of May 2006 when most species had initiated flowering or were just about to set seed. Target grasses were clipped at the soil surface, oven dried at $60^{\circ} \mathrm{C}$ for $24 \mathrm{~h}$, and weighed to the nearest $0.0001 \mathrm{~g}$. After weighing, seeds from the three grass species were removed and counted. All vegetation from the native subplots was similarly harvested and placed into plastic bags until it could be sorted (within 10 days). The vegetation from the uncleared and native background subplots was sorted to species, oven dried at $60^{\circ} \mathrm{C}$ for $24 \mathrm{~h}$, and weighed to the nearest $0.0001 \mathrm{~g}$. Native species biomass was dominated by annuals, but included some perennial bulbs and perennial forbs. There were no non-native species in any of the native subplots.

Soil analysis

In March 2006, two soil cores (4 cm depth, volume $165.2 \mathrm{~cm}^{3}$ ) were taken from each block, except blocks 1 and 2, where only one core was taken because the blocks were close together. For comparison with matrix soil, two soil cores were taken on the same day from a location in the matrix closest to each outcrop core. Soil water content was determined gravimetrically and percent soil moisture was calculated. Soil $\mathrm{NO}_{3}{ }^{-}, \mathrm{NO}_{2}{ }^{-}, \mathrm{NH}_{4}{ }^{+}$, and $\mathrm{P}$ were measured using a Lachat flow injector autoanalyzer following extraction with $\mathrm{KCl}$. Cation concentrations $(\mathrm{Ca}$ and $\mathrm{Mg})$ were 
determined by flame atomic absorption spectrophotometry following extraction with ammonium acetate.

\section{Statistical analyses}

The main effects of resource addition and competition on the biomass and seed production of each of the three nonnative grasses were tested by ANOVA with a model including Resource, Competition, Block (as a random effect), and a Resource $\times$ Competition interaction. To identify which resource addition influenced grass invasion, we conducted a subsequent "resource" ANOVA in which we compared the effect of all single resource addition treatments and the multiple resource addition treatment to the control. To determine if the effect of adding all resources together differed from the sum of the effects of individual resources we included a resource interaction term in this second model. This second ANOVA was also conducted on log-transformed native biomass. For all three non-native grasses, biomass was log transformed and seed number was square root transformed to meet parametric assumptions. Analyses were restricted to plots in which at least one individual germinated and survived (338 out of 384 subplots). All analyses were conducted with JMP IN 5.1 statistical package (SAS Institute, 1989-2003), using the estimated mean square procedure.

A $t$-test was conducted to determine if outcrop and matrix soils differed in moisture, $\mathrm{N}, \mathrm{P}, \mathrm{Ca}, \mathrm{Mg}$, or $\mathrm{Ca}: \mathrm{Mg}$ ratio. $\mathrm{NO}_{3}^{-}, \mathrm{NH}_{4}{ }^{+}$, and $\mathrm{P}$ were analyzed with a non-parametric Wilcoxon test because the assumptions of normality and homoscedasticity could not be met by transformation. $\mathrm{Ca}$ and $\mathrm{Mg}$ concentrations were $\log$ transformed and the $\mathrm{Ca}: \mathrm{Mg}$ ratio was arcsin transformed prior to analyses.

\section{Results}

Plant analyses

Native community biomass increased roughly threefold with the addition of $\mathrm{N}(d f=1, F=10.57, P=0.0025$; from resource ANOVA for N) or all resources together (Fig. 1). There was no significant interactions among resources in their effect on biomass ( $d f=1, F=0.38, P=0.5402)$.

The summed effects of competition and resource limitation severely reduced the growth and reproduction of all three grasses. Avena plants were 10 times more productive and 20 times more fecund in plots with all resources added and competition removed than plants in unmanipulated controls. Similarly, Bromus and Hordeum were, respectively, 4 and 20 times more productive and 6 and 15 times more fecund with the removal of competitors and the addition of all resources.

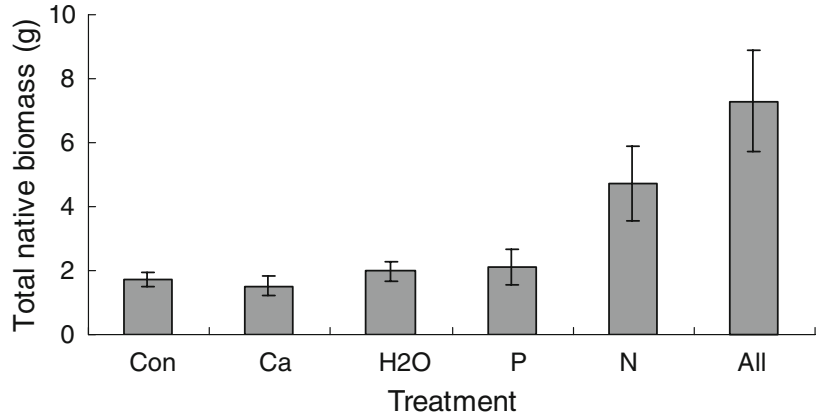

Fig. 1 Biomass of native serpentine vegetation harvested in summer $2006(n=8)$. Nutrient amendments included: no addition (Con), Ca, $\mathrm{H}_{2} \mathrm{O}, \mathrm{P}, \mathrm{N}$, and $\mathrm{N}, \mathrm{P}, \mathrm{Ca}$, and $\mathrm{H}_{2} \mathrm{O}$ together $(\mathrm{All})$. Values are means \pm 1 $\mathrm{SE}$

The individual and interactive effects of resource addition and competition varied among grasses. All three grasses performed better when grown in the absence of competition than when the native community was present. Clearing had a strong, positive effect on the biomass and seed production of all three grasses (Tables 1, 2; Fig. 2). Although the effects of clearing varied somewhat among resource treatments, grass biomass was 2-7 times greater and seed production was 2-9 times greater in cleared versus uncleared control plots.

Of all the resources, $\mathrm{N}$ most often increased the growth and seed production of the grass invaders (Tables 1, 2; Fig. 2). Adding all resources together yielded the greatest biomass and fecundity (Fig. 2), 2-4 times the value in the control plots. $\mathrm{Ca}, \mathrm{H}_{2} \mathrm{O}$, and $\mathrm{P}$ addition had no individual effects on biomass or seed production for any grass species. Resource addition significantly increased the biomass (Fig. 2a) and fecundity (Fig. 2d) of Avena; the $\mathrm{N}$ term in our resource ANOVA was significant (Tables 1,2). The same result was found for Bromus, except that the addition of $\mathrm{N}$ was not significant in the resource ANOVA (Tables 1, 2; Fig. 2b, e). For this species the resources interacted to control biomass and fecundity (Table 2), suggesting colimitation. For Hordeum, which showed high variability in biomass and fecundity, the only significant effect of resource addition was found for biomass (Table 1; Fig. 2c). Still, results were in the same general direction as found for the other two species.

Bromus was the only species to show a significant interaction between resource addition and competition (Tables 1, 2; Fig. 2b, e). In the absence of competition, $\mathrm{N}$ addition marginally increased Bromus biomass and seed production, yet when native competitors were present $\mathrm{N}$ addition reduced Bromus biomass and seed production. $\mathrm{N}$ addition thus increased resistance from the native community as predicted by results in Fig. 1. In contrast to the results for Bromus, competition most effectively reduced the biomass and fecundity of Avena and Hordeum when 
Table 1 ANOVA results (in bold) for the effect of resource addition and competition from the resident serpentine community on the biomass of Avena barbata, Bromus diandrus, and Hordeum murinum

Biomass was log transformed prior to analyses

${ }^{a}$ Results from the "resource ANOVA" to determine the individual and interactive effects of each resource addition on biomass are presented in italics

\begin{tabular}{|c|c|c|c|c|c|c|c|}
\hline \multirow[t]{2}{*}{ Effect } & \multirow[b]{2}{*}{$d f$} & \multicolumn{2}{|l|}{ Avena } & \multicolumn{2}{|c|}{ Bromus } & \multicolumn{2}{|c|}{ Hordeum } \\
\hline & & $F$ & $P$-value & $F$ & $P$-value & $F$ & $P$-value \\
\hline Block & 7 & 7.63 & 0.0001 & 6.53 & 0.0001 & 1.85 & 0.1065 \\
\hline Resource & 5 & 7.51 & 0.0001 & 4.19 & 0.0031 & 4.17 & 0.0043 \\
\hline $\mathrm{Ca}$ & $1^{\mathrm{a}}$ & 0.08 & 0.7800 & 1.27 & 0.2657 & 1.24 & 0.2725 \\
\hline $\mathrm{H}_{2} \mathrm{O}$ & 1 & 0.16 & 0.6903 & 1.18 & 0.2826 & 0.03 & 0.8693 \\
\hline $\mathrm{P}$ & 1 & 2.49 & 0.1191 & 1.26 & 0.2675 & 1.82 & 0.1848 \\
\hline $\mathrm{N}$ & 1 & 7.94 & 0.0063 & 0.09 & 0.7589 & 0.35 & 0.5582 \\
\hline $\mathrm{Ca} \times \mathrm{H}_{2} \mathrm{O} \times \mathrm{P} \times \mathrm{N}$ & 1 & 0.34 & 0.5639 & 4.50 & 0.0387 & 1.66 & 0.2048 \\
\hline Competition & 1 & 25.4 & 0.0001 & 21.3 & 0.0001 & 9.84 & 0.0034 \\
\hline Resource $\times$ Competition & 5 & 0.84 & 0.5271 & 2.65 & 0.0342 & 0.85 & 0.5220 \\
\hline
\end{tabular}

Table 2 ANOVA results (in bold) for the effect of resource addition and competition from the resident serpentine community on the seed production of A. barbata, B. diandrus, and H. murinum

Seed production was square root transformed prior to analyses

${ }^{a}$ Results from the resource ANOVA to determine the individual and interactive effects of each resource addition on seed production are presented in italics

\begin{tabular}{|c|c|c|c|c|c|c|c|}
\hline \multirow[t]{2}{*}{ Effect } & \multirow[b]{2}{*}{$d f$} & \multicolumn{2}{|l|}{ Avena } & \multicolumn{2}{|l|}{ Bromus } & \multicolumn{2}{|c|}{ Hordeum } \\
\hline & & $F$ & $P$-value & $F$ & $P$-value & $F$ & $P$-value \\
\hline Block & 7 & 5.64 & 0.0001 & 4.72 & 0.0004 & 0.66 & 0.7049 \\
\hline Resource & 5 & 6.57 & 0.0001 & 6.58 & 0.0001 & 2.46 & 0.0509 \\
\hline $\mathrm{Ca}$ & $1^{\mathrm{a}}$ & 0.04 & 0.8453 & 0.01 & 0.9417 & 0.16 & 0.6892 \\
\hline $\mathrm{H}_{2} \mathrm{O}$ & 1 & 0.30 & 0.5827 & 0.02 & 0.8877 & 0.004 & 0.9507 \\
\hline $\mathrm{P}$ & 1 & 1.38 & 0.2444 & 0.002 & 0.9647 & 0.96 & 0.3340 \\
\hline $\mathrm{N}$ & 1 & 8.35 & 0.0052 & 0.05 & 0.8228 & 1.20 & 0.2806 \\
\hline $\mathrm{Ca} \times \mathrm{H}_{2} \mathrm{O} \times \mathrm{P} \times \mathrm{N}$ & 1 & 0.16 & 0.6897 & 1.86 & 0.1783 & 0.53 & 0.4702 \\
\hline Competition & 1 & 24.3 & 0.0001 & 14.4 & 0.0004 & 6.47 & 0.0154 \\
\hline Resource $\times$ Competition & 5 & 1.09 & 0.3742 & 5.19 & 0.0002 & 0.56 & 0.7270 \\
\hline
\end{tabular}

resources were more limiting. Control plots with competition showed very little invader biomass and seed production, but when resource-related stresses were eased in the $\mathrm{N}$ or all resource addition plots, invader performance in competitive environments increased greatly (Fig. 2; Avena, biomass $P=0.1299$, seed production $P=0.0422$; Hordeum, biomass $P=0.0271$, seed production $P=0.0359$; from Tukey's HSD post hoc contrast).

\section{Soil analyses}

The soils on the outcrops were $25 \%$ drier and $35 \%$ lower in $\mathrm{NO}_{3}{ }^{-}$than the soils in the matrix (Table 3). Outcrop soils were lower in $\mathrm{Ca}$ and similar in $\mathrm{Mg}$ concentrations as compared to matrix soil (Table 3). The Ca:Mg ratio is a common index of the degree of serpentine (S. Harrison, personal communication) and it was lower in the outcrop soils than matrix soils (Table 3 ).

\section{Discussion}

This study examined the individual and combined effects of two important factors that contribute to community resistance to invasion, resource limitation, and competition from the resident community. Consistent with other invasibility studies, the removal of competition and the addition of limiting resources improved the performance of three grass invaders (Burke and Grime 1996; Barger et al. 2003; Davis and Pelsor 2003), reinforcing the idea that both factors contribute to overall community resistance. However, our study demonstrated a surprisingly large competitive effect of small-statured native plants on large exotic annual grasses, suggesting that biotic resistance may play a larger role than expected in slowing (if not entirely repelling) invasions. In one case, resource availability increased the ability of natives to resist exotic invaders (e.g., a Resource $\times$ Competition interaction), most likely by reducing the availability of another resource, such as light. These results imply that an understanding of interactions between biotic and abiotic factors is needed to understand invasion dynamics. Overall, our study provides key insights into potential conservation strategies in serpentine grassland systems by clarifying the forces that determine the current distribution of native and exotic plants on the landscape.

This study supports the hypothesis that low resource availability can slow plant invasions. $\mathrm{N}$ addition had the greatest positive effect on Avena growth and reproduction 

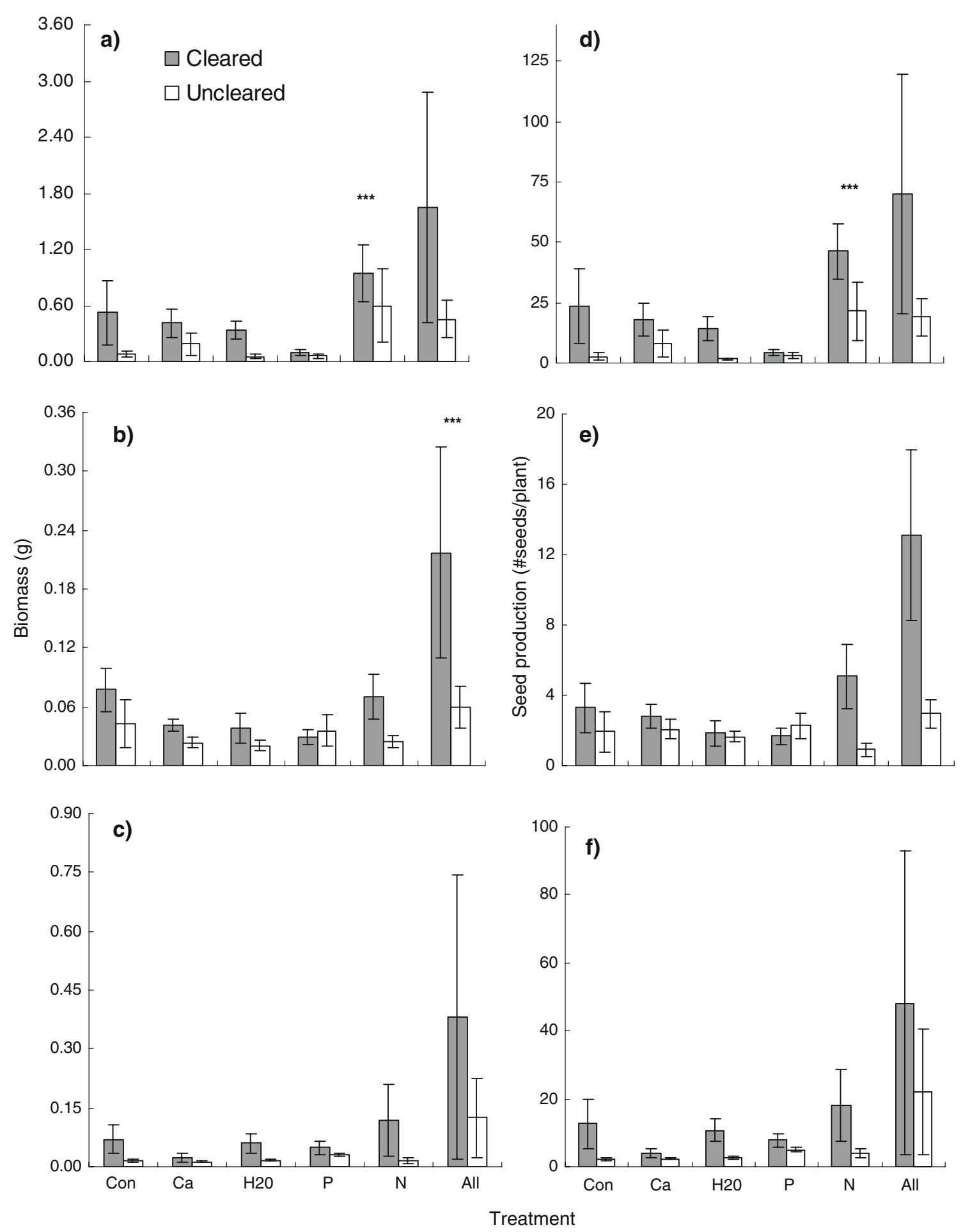

Fig. 2 Biomass and seed production of a, d Avena barbata $(n=8)$, b, e Bromus diandrus $(n=8)$, and $\mathbf{c}$, f Hordeum murinum $(n=8)$ harvested in summer 2006 from cleared and uncleared plots on

and it was one of the resources that differed most between outcrop and matrix soils. For the other two invaders, it was $\mathrm{N}$ in combination with other resources that most increased biomass and fecundity, suggesting co-limitation by these resources. In fact, the other resources, when added serpentine outcrops. Nutrient amendments included: Con, $\mathrm{Ca}, \mathrm{H}_{2} \mathrm{O}, \mathrm{P}$, $\mathrm{N}$, and All. Values are means \pm 1 SE. $* * * P<0.001$. For abbreviations, see Fig. 1

individually, had no effect on invader performance. These results are consistent with those of other studies, which have shown that fertilization increases the invasibility of serpentine grasslands (Turitzin 1982; Huenneke et al. 1990; O'Dell and Claassen 2006). The serpentine outcrops in this 
Table 3 Extractable nutrients, cation concentration, and soil moisture for serpentine outcrops and grassland matrix soils

Values presented are means \pm 1 SE from eight experimental blocks ( $n=1$ for blocks 1 and 2, $n=2$ for blocks 3-8) on serpentine outcrops and adjacent matrix locations

\begin{tabular}{lccccc}
\hline Soil metric & Outcrop & Matrix & $d f$ & $\begin{array}{l}\text { Test } \\
\text { statistic }\end{array}$ & $P$-value \\
& Mean $\pm 1 \mathrm{SE}$ & Mean $\pm 1 \mathrm{SE}$ & & & \\
\hline $\mathrm{NO}_{3}-\mathrm{N}\left(\mu \mathrm{g} \mathrm{g}^{-1}\right)$ & $2.17 \pm 0.34$ & $3.38 \pm 0.42$ & 21 & $Z=2.16$ & 0.0304 \\
$\mathrm{NH}_{4}-\mathrm{N}\left(\mu \mathrm{g} \mathrm{g}^{-1}\right)$ & $0.63 \pm 0.18$ & $0.59 \pm 0.06$ & 14 & $Z=1.36$ & 0.1749 \\
$\mathrm{PO}_{4}-\mathrm{P}\left(\mu \mathrm{g} \mathrm{g}^{-1}\right)$ & $0.06 \pm 0.02$ & $0.02 \pm 0.002$ & 11 & $Z=-1.87$ & 0.0606 \\
$\mathrm{Ca}(\mathrm{mEq} / 100 \mathrm{~g})$ & $2.23 \pm 0.32$ & $3.01 \pm 0.16$ & 18 & $t=-2.79$ & 0.0118 \\
$\mathrm{Mg}(\mathrm{mEq} / 100 \mathrm{~g})$ & $15.81 \pm 1.04$ & $17.64 \pm 0.77$ & 21 & $t=-1.50$ & 0.1490 \\
$\mathrm{Ca}: \mathrm{Mg}$ ratio & $0.14 \pm 0.016$ & $0.17 \pm 0.0048$ & 24 & $t=-2.09$ & 0.0473 \\
Soil moisture $(\%)$ & $21.65 \pm 4.03$ & $28.10 \pm 2.97$ & 22 & $t=-4.46$ & 0.0002 \\
\hline
\end{tabular}

study were not only lower in $\mathrm{N}$ availability, but were also drier and considerably lower in $\mathrm{Ca}$ and $\mathrm{Ca}: \mathrm{Mg}$ ratios than soils in the surrounding matrix (e.g., Huenneke et al. 1990; Harrison 1999; Gram et al. 2004). However, our results suggest that it is the low $\mathrm{N}$, or low $\mathrm{N}$ in combination with other resources that primarily limits the invasion of three invasive grasses, suggesting that metal toxicity is not the primary factor limiting the invasions of these serpentine grasslands by exotic annual grasses.

Our results also show that the native species are limited by the same resources as the invasive grasses, and if anything, this limitation was more severe for the native species. Native biomass also had a strong positive response to the addition of $\mathrm{N}$, but not to $\mathrm{P}, \mathrm{H}_{2} \mathrm{O}$, or $\mathrm{Ca}$ alone. $\mathrm{N}$ and $\mathrm{P}$ limitation have been previously documented for serpentine grasslands (Turitzin 1982; Huenneke et al. 1990; Nagy and Proctor 1997) and several of these studies have reported that the increase in plant biomass from nutrient addition was greatest when $\mathrm{N}$ and $\mathrm{P}$ were provided together (Turitzin 1982; Huenneke et al. 1990). In the absence of competition, $\mathrm{N}$ addition never more than doubled the biomass and fecundity of Avena, Bromus, and Hordeum (Fig. 2), whereas native biomass increased almost threefold (Fig. 1). Possibly this reflects the sensitivity of the invasive species to other stresses of serpentine soil, such as heavy metals, to which the natives are better adapted.

Previous observations of serpentine grasslands have suggested that these grasslands may be more susceptible to invasion by some species in high rainfall years (Hobbs and Mooney 1995; Hobbs et al. 2007). Contrary to our expectations; however, $\mathrm{H}_{2} \mathrm{O}$ addition had no effect on the biomass or seed production of non-native grasses or the biomass of native vegetation in our system. The year in which this study was conducted was an El Niño year, and as a result annual precipitation was above average. It is possible that higher than average precipitation removed $\mathrm{H}_{2} \mathrm{O}$ as a significantly limiting factor in our study year. Even if this is the case, the amount of precipitation received during the study period $(65.3 \mathrm{~cm})$ is not unusual; of the last 18 years, 8 have had $63 \mathrm{~cm}$ of rainfall or more (Western Regional Climate Center 2008). While we expect our results to hold for high rainfall years, it is possible that $\mathrm{H}_{2} \mathrm{O}$ limitation may exert a stronger influence over community resistance in years with average or below average rainfall. It is also important to note that the effect of $\mathrm{H}_{2} \mathrm{O}$ availability on invader success may vary with timing of rainfall.

Our results emphasize the importance of examining the role of the physical environment when determining the controls on biological invasions. They also provide support for recent ecological theory that suggests an increase in resource supply can decrease community resistance to invaders by reducing the intensity of competition for those resources (Davis et al. 2000; Huston 2004). However, an increase in the supply of a limiting resource can potentially increase community resistance if the resident species show a stronger response than the invader (discussed below), thus creating a more competitive environment, or if removing limitation of one resource causes another resource to become limiting.

Native species adapted to serpentine soil are generally considered poor competitors (Brady et al. 2005), and thus, competition has largely been overlooked as a mechanism contributing to community resistance to invasion in serpentine grasslands. However, we found that competition from the resident community had a large negative effect on the success of Avena, Bromus, and Hordeum. The production of biomass and seeds of all three grasses was generally reduced by at least $50 \%$ in plots with intact native background vegetation as compared to plots where native vegetation was removed. This finding was somewhat unexpected because the resident species are all small-statured annuals. We suspect that the decreased performance of the invaders with neighboring annuals is likely due to increased competition for light, as the addition of $\mathrm{N}$ or all resources together transformed the native community from a sparse covering of residents to a system with almost $100 \%$ cover. Moreover, had soil resource competition been the mechanism by which native annuals suppressed nonnative grasses, resource addition would have eliminated the effects of competition, a result that was not observed. While we believe light competition is likely the mechanism for the suppression of invaders, we cannot exclude the possibility 
that other mechanisms, such as changes in microbial biomass or composition, are responsible for the decreased performance of invaders in the presence of the native community.

Our work also suggests important interactions between biotic and abiotic sources of resistance-the characteristics of the physical environment determined the outcome of species interactions (Connell 1961; Pugnaire and Luque 2001; Callaway et al. 2002). We found that the effect of competition from the resident community on Bromus growth and seed production depended on the resource environment. Increasing $\mathrm{N}$ availability enabled the native community to better repel Bromus invasion. These results are inconsistent with current hypotheses of community resistance (e.g., Davis et al. 2000; Huston 2004), which predict that increasing resource supply should decrease competition from resident species. In our study, by contrast, $\mathrm{N}$ addition enhanced the competitive effect of the resident community on Bromus. Thus, in some cases, increasing resource supply can decrease invasibility, depending on the relative responses of the resident community and invader.

For other invaders competition may exert a smaller effect in abiotically stressful environments, but this small effect may be enough to completely repel invaders at the edges of their physiological tolerances (Levine et al. 2004). Indeed, we found that Avena and Hordeum biomass and seed production were exceedingly low in competitive environments in unamended soils $(0.08 \pm 0.03 \mathrm{~g}$ and $0.01 \pm 0.003 \mathrm{~g}$ for Avena and Hordeum, respectively; $2.64 \pm 1.66$ and $2.20 \pm 0.49$ seeds/plant for Avena and Hordeum, respectively), yet much greater when soils were enriched with $\mathrm{N}$ and other resources $(0.45 \pm 0.20 \mathrm{~g}$ and $0.13 \pm 0.10 \mathrm{~g}$ for Avena and Hordeum, respectively, in all treatment; $18.92 \pm$ 7.88 and $22.17 \pm 18.44$ seeds/plant for Avena and Hordeum, respectively, in all treatment) (Fig. 2). Our study provides intriguing evidence of the importance of abioticbiotic interactions in determining the outcome of biological invasions.

Our study is one of only several invasibility studies to examine invader success in terms of both biomass and fecundity. For annual species seed production is more closely related to population growth rate than is biomass and this is particularly true for exotic species without significant seed banks. In several instances invader seed production showed a stronger response than biomass to resource addition and competition. For example, when competitors were removed, Avena seed production increased ninefold, while biomass only increased sevenfold. Similarly, when fertilized, Bromus seed production increased fourfold, compared to only a threefold increase in biomass. These results underscore the importance of including fecundity in community resistance studies.
Collectively, the results of this study demonstrate that the growth and reproduction of three important grassland invaders, Avena barbata, Bromus diandrus, and Hordeum murinum, on serpentine outcrops are constrained by both biotic and abiotic factors and that these factors may interact to determine the success of invasions. These results are consistent with current theories that suggest that native communities are more susceptible to invasion when disturbance events coincide with an increase in resource availability (Burke and Grime 1996; Davis et al. 2000) and support previous work in serpentine grasslands showing a decrease in community resistance from fertilization and disturbance (Koide et al. 1987; Hobbs and Mooney 1995; Hobbs et al. 2007). However, resource addition only sometimes increased invasion success. In fact, for one of our species $\mathrm{N}$ addition reduced its performance due to the enhancement of the native community. Better understanding the relative sensitivities of invaders and residents to the physical environment is critical to predicting how abiotic and biotic factors interact to determine community resistance. For example, in our study, abiotic factors other than low soil resources likely stressed the grass invaders, causing them to be more susceptible to competition from the resident community, which was well adapted to the suite of physical factors that limit productivity on serpentine.

Serpentine ecosystems harbor a high diversity of native species, many of which are endemic to the soil, and our results have important management implications for these systems. Inputs of $\mathrm{N}$ into serpentine ecosystems can alter the competitive dynamics between invaders and the resident community, increasing the invasibility of these ecosystems. Therefore, excessive inputs of $\mathrm{N}$, and other nutrients, should be carefully managed. This may become increasingly difficult if $\mathrm{N}$ deposition rates continue to rise. However, our results also show that the resident community poses an obstacle to invaders. Thus, efforts should be made to manage for intact resident communities by avoiding disturbances that eliminate or reduce resident biomass.

Acknowledgements We thank Melanie Powers, Bree Belyea, Lisa Stratton, Darwin Richardson, and Janet Myers for help with plant collection and Stephanie Yelenik for assistance and advice with the soil analyses. Comments by Susan Harrison and two anonymous reviewers greatly improved this manuscript. B. M. G. was supported by a C. H. Muller award from the University of California, Santa Barbara, and J. M. L. and J. H. R. L. were supported by the David and Lucile Packard Foundation. All experiments complied with the current laws of the United States.

Open Access This article is distributed under the terms of the Creative Commons Attribution Noncommercial License which permits any noncommercial use, distribution, and reproduction in any medium, provided the original author(s) and source are credited. 


\section{References}

Alpert P, Bone E, Holzapfel C (2000) Invasiveness, invasibility and the role of environmental stress in the spread of non-native plants. Perspect Plant Ecol 3:52-66

Barger NN, D'Antonio CM, Ghneim T, Cuevas E (2003) Constraints to colonization and growth of the African grass, Melinis minutiflora, in a Venezuelan savannah. Plant Ecol 167:31-43

Brady KU, Kruckeberg AR, Bradshaw HD Jr (2005) Evolutionary ecology of plant adaptation to serpentine soils. Annu Rev Ecol Evol S 36:243-266

Brooks ML (2003) Effects of increased soil nitrogen on the dominance of alien annual plants in the Mojave Desert. J Appl Ecol 40:344-353

Burke MJW, Grime JP (1996) An experimental study of plant community invasibility. Ecology 77:776-790

Byers JE (2002) Physical habitat attribute mediates biotic resistance to non-indigenous species invasions. Oecologia 130:146-156

Callaway RM, Brooker RW, Choler P, Kilkvidze Z, Lortie CJ, Michalet R, Paolini L, Pugnaire FL, Newingham B, Aschehoug ET, Armas C, Kikodze D, Cook BJ (2002) Positive interactions among alpine plants increase with stress. Nature 417:844-848

Connell JH (1961) The influence of interspecific competition and other factors on the distribution of the barnacle Chthamalus stellatus. Ecology 42:710-723

D'Antonio CM (1993) Mechanisms controlling invasions of coastal plant communities by the alien succulent Carpobrotus edulis. Ecology 74:83-95

D'Antonio CM, Levine J, Thomsen M (2001) Ecosystem resistance to invasion and the role of propagule supply: a California perspective. J Mediterr Ecol 2:233-245

Davis MA, Pelsor M (2003) Experimental support for a resource-based mechanistic model of invasibility. Ecol Lett 4:421-428

Davis MA, Grime JP, Thompson K (2000) Fluctuating resources in plant communities: a general theory of invasibility. J Ecol 88:528-534

Elton CS (1958) The ecology of invasions by animals and plants. Methuen, London

Gram WK, Borer ET, Cottingham KL, Seabloom EW, Boucher VL, Goldwasser L, Micheli M, Kendall BE, Burton RS (2004) Distribution of plants in a California serpentine grassland: are rocky hummocks spatial refuges for native species? Plant Ecol 172:159-171

Harrison SP (1999) Local and regional diversity in a patchy landscape: native, alien, and endemic herbs on serpentine. Ecology 80:70-80

Hobbs RJ, Mooney HA (1995) Spatial and temporal variability in California annual grassland: results from a long-term study. J Veg Sci 6:43-57

Hobbs, RJ, Gulmon SL, Hobbs VJ, Mooney HA (1988) Effects of fertiliseraddition and subsequent gopher disturbance on a serpentine annualgrassland community. Oecologia 75:291-295

Hobbs RJ, Yates S, Mooney HA (2007) Long-term data reveal complex dynamics in grassland in relation to climate and disturbance. Ecol Monogr 77:545-568
Holway DA, Suarez AV, Case TJ (2002) Role of abiotic factors in governing susceptibility to invasions: a test with Argentine ants. Ecology 83:1610-1619

Huenneke LF, Hamburg SP, Koide R, Mooney HA, Vitousek PM (1990) Effects of soil resources on plant invasions and community structure in Californian serpentine grassland. Ecology 71:478-491

Huston MA (2004) Management strategies for plant invasions: manipulating productivity, disturbance, and competition. Divers Distrib 10:167-178

Koide RT, Huenneke LF, Mooney HA (1987) Gopher mound soil reduces growth and affects ion uptake of two annual grassland species. Oecologia 72:284-290

Kruckeberg AR (2006) Introduction to California soils and plants. Serpentine, vernal pools, and other geobotanical wonders. California natural history guides vol. 86. University of California Press, Berkeley

Leishman MR, Thomson VP (2005) Experimental evidence for the effects of additional water, nutrients and physical disturbance on invasive plants in low fertility Hawkesbury Sandstone soils, Sydney, Australia. J Ecol 93:38-49

Levine JM, Adler PB, Yelenik SG (2004) A meta-analysis of biotic resistance to exotic plant invasions. Ecol Lett 7:975-989

Lonsdale WM (1999) Global patterns of plant invasions and the concept of invasibility. Ecology 80:1522-1536

Mitchell CE, Agrawal AA, Bever JD, Gilbert GS, Hufbauer RA, Klironomos JN, Maron JL, Morris WF, Parker IM, Power AG, Seabloom EW, Torchin ME, Vázquez DP (2006) Biotic interactions and plant invasions. Ecol Lett 9:726-740

Nagy L, Proctor J (1997) Plant growth and reproduction on a toxic alpine ultramafic soil: adaptation to nutrient limitation. New Phytol 137:267-274

O'Dell RE, Claassen VP (2006) Relative performance of native and exotic grass species in response to amendment of drastically disturbed serpentine substrates. J Appl Ecol 43:898-908

Pugnaire FL, Luque MT (2001) Changes in plant interactions along a gradient of environmental stress. Oikos 93:42-49

Randall JM, Remanek M, Hunter JC (1998) Characteristics of the exotic flora of California. Fremontia 26:3-12

Richardson DM, Pyšek P (2006) Plant invasions: merging the concepts of species invasiveness and community invasibility. Prog Phys Geog 30:409-431

Siemann E, Rogers WE (2007) The role of soil resources in an exotic tree invasion in Texas coastal prairie. J Ecol 95:689-697

Takemoto BK, Croes BE, Brown SM, Motallebi N, Westerdalh FD, Margolis HG, Cahil BT, Mueller MD, Holmes JR (1995) Acidic deposition in California: findings from a program of monitoring and effects research. Water Air Soil Pollut 85:261-272

Turitzin SN (1982) Nutrient limitation to plant growth in a California serpentine grassland. Am Midl Nat 107:95-99

Western Regional Climate Center (2008). http://www.wrcc.dri.edu. Accessed 18 Jan 2008 